\title{
Safe drinking water: effect of granular activated carbon bed characteristics on iron removal from water
}

\author{
Md. Golam Rasul', Imtiaz Ahmed ${ }^{1}$, Md. Iqbal Hossain ${ }^{1}$
}

${ }^{l}$ Department of Chemical Engineering, Bangladesh University of Engineering and Technology (BUET), Dhaka-1000, Bangladesh. Article Info: Submitted on June 20, 2015, Accepted on December 8, 2015.

\begin{abstract}
Tuning the characteristics of granular activated carbon bed (GAC-bed) in household water-filters would be a technique to maintain iron at the required-level in drinking water. In the present study the individual effects of the depth of GAC-bed and the size and porosity of GAC particles on the iron removing capacity are investigated experimentally. A spectrophotometer is used to measure iron-content in water. It is observed that iron removing capacity increases monotonically with the increase in bed-depth regardless of the size of GAC particles. It is also observed that the iron removing capacity decreases drastically with the increase in the size of GAC particles for any fixed bed-depth. Finally the porosity of GAC particles is found to affect the iron removing capacity. The higher the GAC porosity the higher is the iron removing capacity over the considered porosity-range. It is believed that the observations of present study would be useful in adjusting GAC-bed characteristics at the time of designing household water-filters to maintain iron at the required-level.
\end{abstract}

Keywords: Safe drinking water; Water-filters; Iron content; Activated carbon; Bangladesh.

\section{Introduction}

Natural wearing of iron bearing minerals and rocks always leave iron in groundwater. ${ }^{1}$ Industrial effluents, acid-mine drainage, sewage and landfill leachate also introduce iron into water. ${ }^{1}$ The iron injected into human body via drinking-water is related to crucial biological functions. ${ }^{2}$ The most important function that iron performs is the formation of hemoglobin which in turn carries and delivers oxygen to all oxygenrequiring cells of the body. ${ }^{2}$ Iron is used in cellular metabolism and also required for the regular activities of numerous enzymes in the body. ${ }^{3}$ Hence insufficiency of iron in the body can lead to irondeficiency, anemia and fatigue. ${ }^{3,4}$ It also can make human body more susceptible to infections. ${ }^{3}$ On the other hand, the presence of iron in human body at an excessive-amount affects mental and nervous functions adversely. ${ }^{5}$ It also can cause damage in bloodcomposition, lungs, kidneys, liver and other essential organs. ${ }^{6}$ The drinking water is consequently required to contain iron in adequate proportions. According to the international standards, iron is required to be in the range of $0.1-0.3 \mathrm{mg} / \mathrm{L}$ in drinking water. ${ }^{7,8}$ However the raw drinking-water is found to carry iron in excessive proportions in many geographical regions of Bangladesh. $^{7}$ Thus filtering the raw drinking-water is essential to make it safe for drinking purpose. As a result, various commercial household water-filters have traditionally been used to purify the water to be used for drinking purpose. ${ }^{9}$

To observe experimentally the effect of waterfiltration, the drinking waters obtained from various sources were filtered by several household water-filters in laboratory prior to the present study. The average results of laboratory-testing are presented in Table 1. It can be seen from Table 1 that the household waterfilters reduce the iron-content to $0.0055 \mathrm{mg} / \mathrm{L}$ while the minimum requirement of iron in drinking water is $0.1000 \mathrm{mg} / \mathrm{L} .^{7,8}$ This excessive reduction in ironcontent is certainly a threat for good-health unless an appropriate measure is taken to add iron separately at the right proportion before drinking the water. Hence the design and operation of household water-filters require more attention.

Table 1: Effect of water-filtration using commercial household water-filters.

\begin{tabular}{|l|c|c|}
\hline Minerals & $\begin{array}{c}\text { Content before } \\
\text { filtering }(\mathrm{mg} / \mathrm{L})\end{array}$ & $\begin{array}{c}\text { Content after } \\
\text { filtering }(\mathrm{mg} / \mathrm{L})\end{array}$ \\
\hline Iron & 0.693 & 0.0055 \\
\hline Copper & 0.156 & 0.1390 \\
\hline Manganese & 0.220 & 0.0160 \\
\hline Nickel & 0.007 & 0.0010 \\
\hline Magnesium & 1.550 & 0.1000 \\
\hline
\end{tabular}

To filter-out minerals from water, the household waterfilters employ a GAC-bed due to the micro-porous structure, chemically-active surface and high surface area of GAC particles. ${ }^{9-17}$ Tuning the characteristics of GAC-bed would therefore be a technique to maintain iron at the required-level in drinking water. Nevertheless proper experimental data on the effect of GAC-bed characteristics on the removal of iron from water is not available in literature. Hence the main objective of this study is to investigate the effect of OBangladeshUni.ofEngg.\&Tech 1 


\section{Chemical Engineering Research Bulletin 18(2015) 1-5}

GAC-bed characteristics on the removal of iron from water. Particularly the individual effects of the depth of GAC-bed and the size and porosity of GAC particles are investigated in this study.

\section{Materials and Methods}

The schematic of experimental setup used to determine iron removing capacities at various conditions is shown in Fig. 1. The setup consists of a feed reservoir having $40 \mathrm{~L}$ volume, three columns made of acrylic and having $60 \mathrm{~cm}$ length and $6 \mathrm{~cm}$ diameter, and a drain tank having $10 \mathrm{~L}$ volume. There is a regulating valve below the underneath of feed reservoir to control the discharge flow rate. The feed reservoir is charged with water obtained mixing equal-volume of drinking waters from three different sources. The iron-content of mixed water is $0.693 \mathrm{mg} / \mathrm{L}$. Iron-content in water is measured employing a scanning spectrophotometer. ${ }^{18}$ Prior to the scanning in spectrophotometer for ironcontent, the water sample is mixed with FerroVer Iron Reagent (1, 10 phenanthroline) which recovers total soluble ferrous and ferric iron, as well as complex iron compounds and many insoluble iron forms.

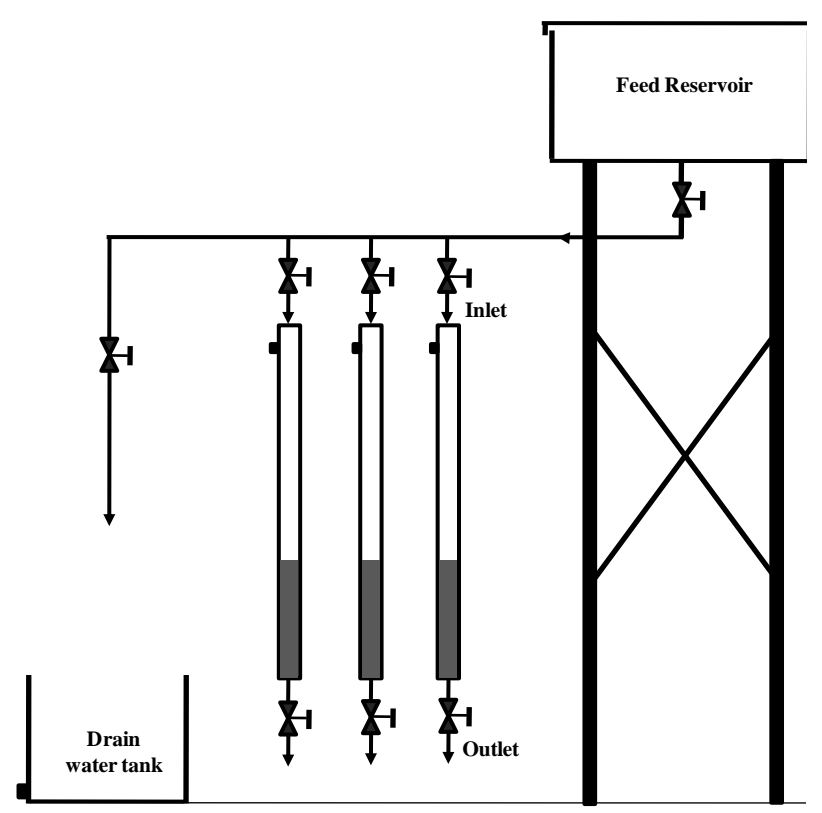

Figure 1: Experimental setup used in the determination of iron removing capacity.

Each column in Fig. 1, which is to be charged with GAC particles for removing iron from water, is also accompanied with a pair of flow-regulating valves. The bottom of each column is equipped with a polymeric screen with $0.10 \mathrm{~cm}$ mesh size to prevent the GAC particles from leaving the bed. The activated carbon is collected from local supplier. The collected activated carbon is grinded using a small laboratoryscale ball-mill grinder. An ASTM sieve analysis is subsequently performed to obtain GAC particles of the average sizes of $0.120,0.155,0.204,0.287$ and 0.406 $\mathrm{cm}$. To remove foreign dirt from GAC particles, the particles are washed carefully with distilled water. The washed particles are finally dried in an oven at $102^{\circ} \mathrm{C}$ for $24 \mathrm{hrs}$ to eliminate moisture. For quantifying the porosity $\phi$ of GAC particles, it is required to define porosity by the equation given below:

$\phi=\frac{V_{p}}{V_{b}}$

where $V_{b}$ and $V_{p}$ are respectively the bulk volume and pore volume of GAC particles. $V_{b}$ is measured by displacement method with the help of a calibrated Pycnometer. ${ }^{19}$ On the other hand, $V_{p}$ is measured experimentally by a gas expansion porositymeter. ${ }^{20}$ The depth of GAC-bed in a column is measured by calibrated scale.

In the course of the operation in experimental setup, the feed-water is discharged from the reservoir through the columns filled with GAC particles as shown by grey-shade in Fig. 1 keeping the valves associated with the columns open. The water samples are then collected simultaneously from the outlet of each column right after a fixed time of two minutes counted from the moment at which water starts to appear in the outlet of each column. The iron-contents in the collected water samples are measured in the scanning spectrophotometer as described earlier. ${ }^{19}$ The difference in iron-content between the feed-water and collected sample-water is taken as the measure of the iron removing capacity at the respective condition. The iron removing capacity at $i^{\text {th }}$ condition is defined mathematically by the equation given below:

Iron removing capacity $\mathrm{i}_{\mathrm{i}}=\frac{C_{\text {iron. feed }}-C_{\text {iron.outlet, },}}{C_{\text {iron.feed }}} 100 \%$

where $C_{\text {iron.feed }}$ and $C_{\text {iron.outlet }}$ are the iron-contents of feed and outlet waters respectively. $C_{\text {iron.feed }}$ remains fixed throughout the full course of this study. The arithmetic mean of the iron removing capacities of three columns under an identical condition is used as the average iron removing capacity for the same condition.

\section{Results and Discussion}

The effect of GAC-bed depth on the iron removing capacity is discussed at first. The individual effects of the size and porosity of GAC particles on iron removing capacity are analyzed subsequently. 


\section{Chemical Engineering Research Bulletin 18(2015) 1-5}

\section{Effect of the depth of GAC-bed}

The depths of GAC-bed considered in this investigation are ranged from 1.5 to $13.0 \mathrm{~cm}$. The effect of bed-depth on the iron removing capacity is studied for two different sizes of GAC particles such as 0.287 and $0.406 \mathrm{~cm}$. The effect of bed-depth is investigated at two different sizes to ensure the reproducibility of experimental observation. It is seen from Fig. 2 that the iron removing capacity increases monotonically when the bed-depth is increased from 1.5 to $13.0 \mathrm{~cm}$ for both particle sizes. This is probably due to the reason that the contact or retention time of iron-containing water in the GAC-bed increases with the increase in bed-depth. The higher the bed-depth the higher is the iron removing capacity. Hence adjusting bed-depth can be a means to maintain iron at the right proportions in drinking water.

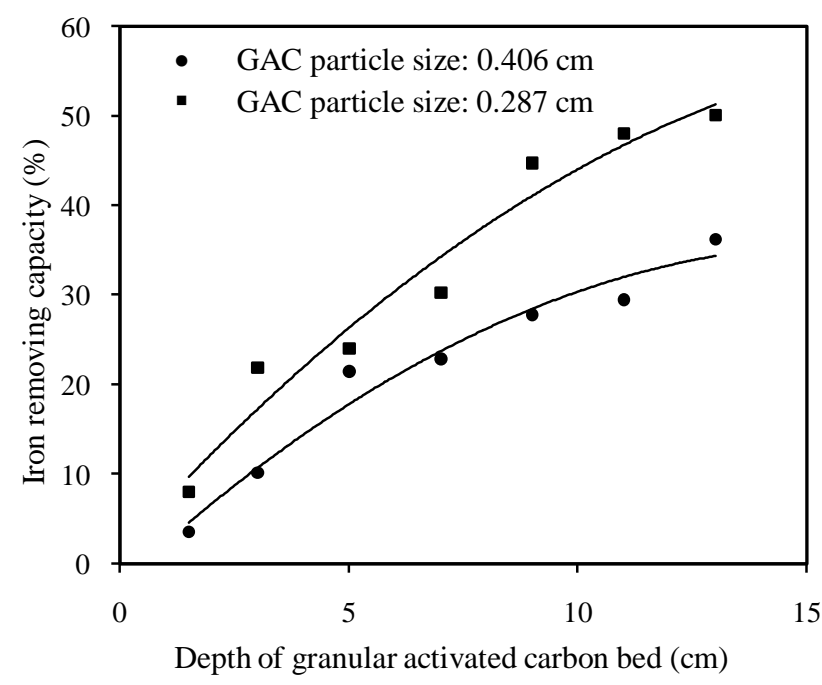

Figure 2: Effect of the depth of granular activated carbon bed on iron removing capacity (\%).

\section{Effect of the size of GAC particles}

The average sizes of GAC-particles used for investigating their effect on iron removing capacity are $0.120,0.155,0.204$ and $0.406 \mathrm{~cm}$. Two fixed beddepths of 3.0 and $5.0 \mathrm{~cm}$ are used. It can be seen from Fig. 3 that iron removing capacity decreases drastically with the increase in GAC particle size for the both beddepths. It can therefore be concluded that iron removing capacity of GAC-particles decreases remarkably with the increase in their size. As a reason of this effect, it is hypothesized that when the size of GAC particles increases, the surface area available for removing iron from water decreases resulting in a corresponding decrease in iron removing capacity. Thus tuning the size of GAC-particles is certainly an option to keep iron-content at its required values in drinking water.

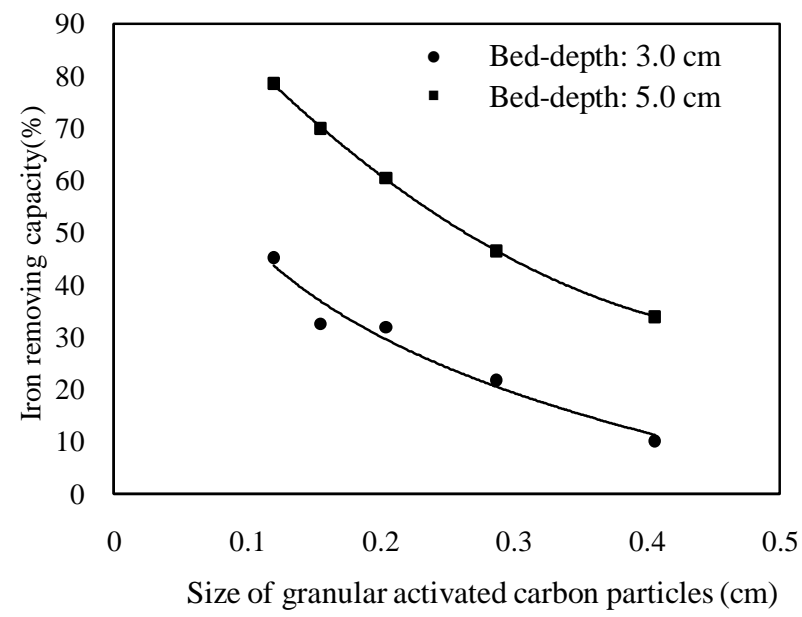

Figure 3: Effect of the size of granular activated carbon particles on iron removing capacity.

\section{Effect of the porosity of GAC particles}

Being related to the surface area intrinsically the porosity of GAC particles is anticipated to affect the iron removing capacity. The effect of porosity is consequently studied considering four different GAC samples with porosity ranges from 0.181 to 0.566 . The size and bed-depth of GAC samples used are 0.407 and $5.0 \mathrm{~cm}$ respectively. It can be seen from Table 2 that iron removing capacity is extremely low at the GAC porosities of 0.181 and 0.274. However the observations at these two porosities reveal that iron removing capacity tends to increase with the increase in porosity. This behavior becomes obvious when the porosity is increased more from 0.274 to 0.521 . There is a huge increase $(0.70$ to $18.84 \%)$ in the iron removing capacity when the porosity is increased from 0.274 to 0.521 . The increasing behavior of iron removing capacity remains valid if the porosity is increased further from 0.521 to 0.566 . As a result it is stated that the iron removing capacity of GAC particle increases monotonically with the increase in porosity over the range taken into consideration in this study. This result is related to an established principle. It is known that the increase in porosity always tends to increase the surface area of porous materials. The increased surface area in turn functions to enhance both the physical/chemical phenomena. Hence the observed effect of the porosity of GAC particles is believed to be caused from the resulted change in the surface area of GAC particles. Nevertheless the porosity of GAC particles can also be considered as a variable to control iron-content in drinking water. 


\section{Chemical Engineering Research Bulletin 18(2015) 1-5}

Table 2: Effect of GAC particles porosity on iron removing capacity.

\begin{tabular}{|l|c|c|}
\hline GAC sample & Porosity & $\begin{array}{c}\text { Iron removing capacity } \\
(\%)\end{array}$ \\
\hline GAC-01 & 0.181 & 0.35 \\
\hline GAC-02 & 0.274 & 0.70 \\
\hline GAC-03 & 0.521 & 18.94 \\
\hline GAC-04 & 0.566 & 22.82 \\
\hline
\end{tabular}

\section{Conclusion}

Iron in drinking water is to perform a number of crucial biological functions in human body. It is therefore always required to be present at the right proportions in drinking water. A GAC-bed is mostly used in household water-filters to refine water to be used for drinking purpose. Hence the individual effects of GAC-bed characteristics (i.e. bed-depth and the size and porosity of GAC particles) on iron removing capacity are studied experimentally in the present research. An increase in the depth of GAC-bed is found to increase the iron removing capacity substantially over the entire range of bed-depth considered. However the size of GAC particles exhibits a substantial reverse effect. It is observed for different fixed bed-depths that the higher the size of GAC particles the lower is the iron removing capacity. Finally the increase in the porosity of GAC particles is also found to increase the iron removing capacity remarkably. All these experimental observations prove the feasibility of tuning GAC-bed characteristics in household water-filters as a technique to control iron content in drinking water. The results presented here can subsequently be utilized for the development and validation of proper mathematical model to represent the influences of GAC-bed characteristics on iron removing capacity at various conditions.

\section{Acknowledgement}

Support from the Department of Chemical Engineering, Bangladesh University of Engineering and Technology (BUET) and financial aid from Abbott Vascular Ltd., USA are gratefully acknowledged.

\section{References}

1. M. A. Charette and E. R. Sholkovitz, "Oxidative precipitation of groundwater-derived ferrous iron in the subterranean estuary of a coastal bay," vol. 29, no. 10, February 2002.

2. "United States Environmental Protection Agency," [Online]. Available: www.epa.gov. [Accessed 20 March 2014].
3. A. von Drygalski and J. W. Adamson, "Iron metabolism in man," Journal of Parenteral and Enteral Nutrition, vol. 37, no. 5599-606, 2012.

4. M. E. Shils and M. Shike, Modern Nutrition in Health And Disease, 10th ed., Baltimore: Lippincott Williams \& Wilkins, 2006, p. 248-70.

5. "World Health Organization," 2003. [Online]. Available:http://www.who.int/water_sanitation_he alth/GDWQ/draftchemicals/manganese2003.pdf. [Accessed March 2014].

6. D. W. Killilea, H. Atamna, C. Liao and B. N. Ames, "Iron accumulation during cellular senescence in human fibroblasts in vitro," Antioxidants and Redox Signaling, vol. 5, no. 5, pp. 507-516, 2003.

7. "Bangladesh National Drinking Water Quality Survey of 2009," 2009. [Online]. Available: http://www.unicef.org/bangladesh. [Accessed 27 January 2014].

8. "National Secondary Drinking Water Standards," [Online]. Available: http://www.waterresearch.net/index.php/standards/secondarystandards. [Accessed 5 january 2014].

9. T. Otowa, Y. Nojima and T. Miyazaki, "Development of $\mathrm{KOH}$ activated high surface area carbon and its application to drinking water purification," Carbon, vol. 35, no. 9, pp. 1315-19, 1997.

10. A. C. Lua and J. Guo, "Adsorption of sulfur dioxide on activated carbon from oil-pam waste," Journal of Environmental Engineering, vol. 127, no. 10, pp. 889-894, 2001.

11. H. Pignon, C. Brasquet and P. Le Cloirec, "Coupling ultrafiltration and adsorption onto activated carbon cloth: application to the treatment of highly colouredwastewaters.," Water Science Technology, vol. 42, no. 5/6, pp. 355-362, 2000.

12. G. L. Culp and R. L. Culp, "New Concepts in water purification," 1974.

13. J. S. Mattson and H. B. Mark, "Activated carbon: surface chemistry and adsorption from solution," New York, M. Dekker, 1971.

14. B. Khalfaoui, A. H. Meniai and R. Borja, "Removal of copper from industrial wastewater by raw charcoal obtained from reeds," Journal of chemical technology and biotechnology, vol. 64, no. 2, pp. 153-56, 1995.

15. S. A., M. P., G. C. and F. J., Chemistry and Physics of Carbon, J. Chem. Technology, 1996.

16. K. Kadirvelu, C. Faur-Brasquet and P. L. Cloirec, "Removal of $\mathrm{Cu}$ (II), $\mathrm{Pb}$ (II), and $\mathrm{Ni}$ (II) by adsorption onto activated carbon cloths," Langmuir, vol. 16, no. 22, pp. 8404-9, 2000.

17. P. Malik, "Dye removal from waste water using activated carbon developed from sawdust: adsorption equilibrium and kinetics," Journal of 


\section{Chemical Engineering Research Bulletin 18(2015) 1-5}

Hazardous Materials, vol. 113, no. 1, pp. 81-88, 2004.

18. L. Monser and N. Adhoum, "Modified activated carbon for the removal of copper, zinc, chromium and cyanide from wastewater," Separation and purification technology, vol. 26, no. 2, pp. 137146, 2002.

19. Y. Salissous and R. Panneton, "Pressure/mass method to measure open porosity of porous solids," Journal of Applied Physics. 101, 124913(2007).

20. Basic Properties of Reservoir Rocks, (C) Copyright by Dr. Sidqi A. Abu-Khamsin, August 2004. King Fahd University of Petroleum \& Minerals Dhahran, Saudi Arabia.

\section{Available online at http://www.banglajol.info/index.php/CERB}

Publisher: Department of Chemical Engineering, Bangladesh University of Engineering and Technology (BUET). Review \&Publication: A submitted original manuscript is taken into review only if the uniqueness is found to be more than $85 \%$ in plag-scanning and selected for publication by the complete acceptance from at least two reviewers out of three. Home Page: http://www.banglajol.info/index.php/CERB . Indexed by Chemical Abstract Service (CAS), CEABA-VtB, Google Scholar, Scopus and DOAJ. 